\title{
Effect of nebulised recombinant DNase on neutrophil elastase load in cystic fibrosis
}

\author{
Christine M Costello, Clare M O'Connor, Geraldine A Finlay, Paul Shiels, \\ Muris X FitzGerald, James P Hayes
}

\begin{abstract}
Background - DNA released by degenerating inflammatory neutrophils contributes to mucous plugging of airways in patients with cystic fibrosis. Neutrophil elastase, a major effector of tissue destruction in the lungs of patients with cystic fibrosis, is a highly cationic molecule which is bound and inhibited by negatively charged polyanions such as mucin and DNA in purulent sputum. Thus, the solubilisation of DNA in the airways by aerosolised recombinant DNase may remove a source of neutrophil elastase inhibition, effectively increasing elastase load. The aim of this study was to assess the effect of rhDNase therapy on neutrophil elastase load in patients with cystic fibrosis.
\end{abstract}

Methods - Blood and sputum were collected from 15 patients with cystic fibrosis before initiation of nebulised DNase therapy and at 12 weeks following therapy. The long term effects of continuous rhDNase administration were evaluated at 52 weeks for 11 of these patients. Plasma was analysed for neutrophil elastase, interleukin (IL)-8 and neutrophil elastase in complex with $\alpha_{1}$-protease inhibitor $\left(\alpha_{1} P I\right)$. Sputum was assessed for neutrophil elastase, IL-8, and active elastase. At each visit spirometric measurements were carried out.

Results - Sputum elastase activity decreased at 12 weeks and was maintained at 52 weeks when a decline in total plasma elastase was also observed. Although, as expected, there was a correlation between plasma levels of total elastase and neutrophil elastase $/ \alpha_{1}$ PI complex, the decrease in the levels of the complex at 52 weeks did not reach statistical significance.

Conclusions - This study indicates that prolonged daily administration of rhDNase results in a reduction in elastase load in patients with cystic fibrosis.

(Thorax 1996;51:619-623)

Keywords: cystic fibrosis, recombinant DNase, neutrophil elastase.

Airway obstruction caused by the accumulation of tenacious viscid secretions in the bronchi is the hallmark of respiratory disease in cystic fibrosis. DNA derived from the disintegration of inflammatory cells, particularly neutrophils, is a major contributor to the viscosity of airway secretions and is present in very high concentrations in the sputum of patients with cystic fibrosis. ${ }^{1}$ As early as the 1950 s it was shown that DNase isolated from bovine pancreas reduced sputum viscosity both in vitro and in vivo, suggesting that aerosolised administration of DNase might alleviate airway obstruction in patients with cystic fibrosis. ${ }^{23}$ Following reports of severe adverse respiratory reactions such as bronchospasm, however, treatment with bovine DNase was largely abandoned. ${ }^{4}$ Recently, the successful cloning and production of recombinant human DNase (rhDNase) has revived interest in DNase therapy. ${ }^{5}$ Results from clinical trials indicate that daily administration of aerosolised rhDNase evokes a moderate but sustained improvement in pulmonary function and a decrease in the incidence of infective exacerbations. ${ }^{6-10}$ To date, however, no study has examined the effect of long term rhDNase therapy on the underlying inflammation in cystic fibrosis.

Chronic pulmonary inflammation, characterised by a massive influx of neutrophils from the bloodstream, is now regarded as the immediate cause of lung destruction and disease in cystic fibrosis. ${ }^{1011}$ Conventionally assumed to be a response to sustained bacterial infection of the bronchial mucosa, recent studies suggest that inflammation may actually precede infection. ${ }^{12}$ Whatever the initial sequence of events, an inflammatory cascade resulting in the continual influx, activation, and disintegration of neutrophils is established in the lung. As indicated above, DNA released from disintegrating neutrophils contributes significantly to sputum viscosity and mucous plugging of the airways. Another product of activated and disintegrating neutrophils, neutrophil elastase, is thought to be a major effector of tissue damage and destruction in the lungs of patients with cystic fibrosis. ${ }^{1013}$ This enzyme can degrade structural proteins, directly damage bronchial cells, and induce local immunoincompetence. ${ }^{14-17}$ It can also perpetuate neutrophil influx by releasing $\mathrm{C} 5 \mathrm{a}$ from complement and stimulating production of interleukin-8 (IL-8) by alveolar macrophages and airway cells. ${ }^{1819}$ Several studies have shown a direct relationship between sputum elastase and disease severity in cystic fibrosis, with highest levels of enzyme being observed in patients with severe lung disease. ${ }^{2021}$ Given the destructive potential of neutrophil elastase and its direct association with disease severity in cystic fibrosis, there is a need to ensure that, at minimum, administered rhDNase does not adversely affect the pulmonary elastase load. Approximately $90 \%$ of the total protease in 
sputum from patients with cystic fibrosis is associated with DNA and mucin, which inhibit its activity. ${ }^{22}$ In vitro studies have shown that rhDNase releases sequestered proteases from DNA, resulting in an increase in free neutrophil elastase activity. ${ }^{2324}$ This raises the possibility that solubilisation of DNA in the airways may remove a source of enzyme inhibition, effectively increasing the elastase load.

The aim of this study was to assess the effect of rhDNase therapy on the neutrophil elastase load in patients with cystic fibrosis. In light of the proinflammatory role of IL-8 in attracting neutrophils to the lung, the effect of rhDNase treatment on IL-8 levels was also assessed. The study was designed to enable evaluation of medium term (12 weeks) and long term (52 weeks) effects of continuous rhDNase administration.

\section{Methods}

STUDY DESIGN

Fifteen adult patients with cystic fibrosis (eight women) aged 17-29 years were recruited in an open study. Patients were required to have a forced vital capacity (FVC) of $40-70 \%$ of predicted and to have proven cystic fibrosis as demonstrated by a positive sweat test or DF508/DF508 genotype. All patients were given $2.5 \mathrm{mg}$ rhDNase (Genentech) daily via a Hudson T-Updraft II Jet nebuliser which was connected to a PulmoAide compressor (Roche Products Ltd, Hertfordshire, UK). Patients continued on physiotherapy, and medications including aerosolised antibiotics, $\beta$ agonists, methylxanthines, corticosteroids, pancreatic enzymes and vitamin supplements were maintained throughout the study. All acute infective episodes were recorded. Intravenous antibiotics were given as clinically indicated. Patients were assessed at entry to the study and at 11-12 and 49-57 weeks following initiation of rhDNase therapy. At each visit spirometric tests were carried out according to the guidelines of the American Thoracic Society at the same time on each visit day and blood and sputum samples were taken. The study was approved by the St Vincent's Hospital ethical committee and written informed consent was obtained from all patients.

\section{SAMPLE PROCESSING AND ANALYSIS}

Sputum samples were maintained at room temperature and processed within one hour of collection to prevent neutrophil degranulation following sampling. A volume of $0.07 \mathrm{M}$ sodium phosphate buffer (pH 6.0 , containing $0.5 \mathrm{M}$ $\mathrm{NaCl}$ and $50 \mu \mathrm{g} / \mathrm{ml}$ dithiothreitol) equivalent to five times the sputum weight was added and the sample gently agitated (manually) until a uniform suspension was obtained. This suspension was then divided into two equal aliquots. To one aliquot the serine protease inhibitors, phenylmethylsulphonyl fluoride (PMSF) and di-isopropyl fluorophosphate (DIPF), and the metalloproteinase inhibitors, ethylenediamine tetraacetic acid (EDTA) and phenanthroline (PA), at a final concentration of $10 \mathrm{mM}$, were added to prevent proteolysis following sampling. The second aliquot was retained without the addition of inhibitors to enable assessment of enzyme activity. All aliquots were centrifuged at $30000 \mathrm{~g}$ for 30 minutes and the resulting supernatants were stored at $-70^{\circ} \mathrm{C}$ prior to analysis. To fully evaluate elastase load, sputum samples were analysed for elastase activity and total immunoreactive elastase. Levels of the neutrophil chemoattractant IL-8 were also assessed.

Sodium citrate was used as anticoagulant for the collection of blood samples. Plasma was collected by centrifugation at $350 \mathrm{~g}$ for 10 minutes and stored at $-70^{\circ} \mathrm{C}$ until assayed. As elastase is rapidly bound and iractivated by inhibitors when it enters the bloodstream, it was assessed in plasma samples by measurement of total immunoreactive elastase and elastase complexed to $\alpha_{1}$ PI. Plasma IL- 8 levels were also assessed.

\section{Assessment of neutrophil elastase activity}

Sputum samples that did not contain protease inhibitors were assayed for elastase activity using the chromogenic peptide substrate $N$-methoxysuccinyl-Ala-Ala-Pro-Val p-nitroanilide (Sigma, Poole, UK) at a concentration of $4.2 \mathrm{mM} \cdot{ }^{25}$ Using an extinction coefficient of $8800 / 1 / \mathrm{mol} / \mathrm{cm}$, molar concentrations of peptide hydrolysed were determined and enzyme units, defined as the release of $1 \mathrm{M} p$-nitroanilide $/ \mathrm{min} / \mathrm{ml}$ sputum, were calculated.

\section{Assessment of total immunoreactive neutrophil} elastase

An indirect ELISA for the measurement of neutrophil elastase was used to assay total elastase levels in sputum and plasma samples. Briefly, a 96-well microtitre plate was coated overnight with neutrophil elastase in sodium carbonate buffer, $\mathrm{pH} 9.6$, containing $1.75 \mathrm{mM}$ PMSF. The plate was washed with phosphate buffered saline (PBS) $/ 0 \cdot 1 \%$ Tween and nonspecific binding sites were blocked with PBS/ $1 \%$ bovine serum albumin for one hour at $37^{\circ} \mathrm{C}$. Standards and samples were incubated with an equal volume of sheep anti-human neutrophil elastase antibody (Serotec, Oxford, UK) diluted to a final concentration of $1 \mathrm{mg} /$ $\mathrm{ml}$ protein containing $1.75 \mathrm{mM}$ PMSF for two hours at $37^{\circ} \mathrm{C}$. The plate was washed in PBS/ Tween and standards and samples were added to triplicate wells and incubated for two hours at $37^{\circ} \mathrm{C}$. After washing five times the wells were incubated with rabbit anti-sheep IgG (whole molecule) antibody (Sigma, Poole, UK) at a final concentration of $0.15 \mathrm{mg} / \mathrm{ml}$ for $30 \mathrm{~min}$ utes at $37^{\circ} \mathrm{C}$. After five washes goat anti-rabbit IgG-horse radish peroxidase conjugate (Promega, Madison, USA) diluted 1:10000 was added to wells and incubated for 30 minutes at $37^{\circ} \mathrm{C}$. The plate was washed 10 times, the substrate o-phenylenediamine (BDH Chemicals, Poole, UK) in $0.1 \mathrm{M}$ citric acid ( $\mathrm{pH} \mathrm{5.0)}$ buffer was added to each well and incubated at room temperature in the dark for five minutes. The reaction was stopped by the addition 
Table 1 Mean (SE) and range of baseline pulmonary function levels and percentage change from baseline at 12 and 52 week intervals

\begin{tabular}{lll}
\hline & $F E V_{1}$ & $F V C$ \\
\hline Baseline \% predicted & $34 \cdot 7(2 \cdot 1)$ & $52 \cdot 7(2 \cdot 3)$ \\
& $(23$ to 51$)$ & $(41$ to 69$)$ \\
\% Change at 12 weeks & $1 \cdot 46(5 \cdot 46)$ & $1 \cdot 04(5 \cdot 6)$ \\
\% Change at 52 weeks & $(-33$ to -46$)$ & $(-32$ to -53$)$ \\
& $(-47 \cdot 13$ to -46$)$ & $\begin{array}{l}-4 \cdot 45(8 \cdot 7) \\
(-50 \text { to }-56)\end{array}$ \\
\hline
\end{tabular}

of $4 \mathrm{~N} \mathrm{H}_{2} \mathrm{SO}_{4}$ and absorbance read at $490 \mathrm{~nm}$ (Biotek microplate reader, EL-309, Vermont, USA).

Assessment of neutrophil elastase/ $\alpha_{1}$ PI complexes Neutrophil elastase bound to $\alpha_{1}$ PI was measured in plasma samples by a double ligand ELISA (Merck, Darmstadt, Germany). Samples were added to plastic tubes coated with anti-neutrophil elastase antibody and incubated at $20^{\circ} \mathrm{C}$ for one hour. An alkaline phosphatase-conjugated antibody to $\alpha_{1}$ PI was then added and incubated at $20^{\circ} \mathrm{C}$ for $30 \mathrm{~min}$ utes. Following washing to remove excess antibody, the enzyme activity of the complexed alkaline phosphatase was measured photometrically using 4-nitrophenyl phosphate as substrate. Absorbances were read at $405 \mathrm{~nm}$ (Ultrospec Plus, Uppsala, Sweden).

\section{Assessment of $I L-8$}

IL-8 levels in sputum and plasma samples were measured with a commercially available human IL-8 immunoassay kit ( $\mathrm{R} \& \mathrm{D}$ systems, Oxon, UK). In brief, standards and samples were added to a 96 well ELISA plate coated with monoclonal antibody specific for IL-8. After washing, an enzyme linked polyclonal antibody followed by a substrate solution (stabilised hydrogen peroxide and chromogen tetramethylbenzidine) resulted in colour development. Absorbance was measured at dual wavelength $450 / 540 \mathrm{~nm}$ (Biotek microplate reader, EL-309, Vermont, USA).

\section{DATA ANALYSIS}

Measurements before and after rhDNase were compared using the Wilcoxon signed rank test. A p value of less than 0.05 was considered

Table 2 Mean (SE) and range of plasma and sputum levels of elastase before and after rhDNase therapy

\begin{tabular}{|c|c|c|c|}
\hline & $\begin{array}{l}\text { Before } \\
\text { rhDNase }\end{array}$ & $\begin{array}{l}12 \text { weeks after } \\
\text { rhDNase }\end{array}$ & $\begin{array}{l}52 \text { weeks after } \\
\text { rhDNase }\end{array}$ \\
\hline \multicolumn{4}{|l|}{ Plasma: } \\
\hline Total elastase $(\mathrm{ng} / \mathrm{ml})$ & $\begin{array}{l}242 \cdot 0(34 \cdot 6) \\
(120-542)\end{array}$ & $\begin{array}{l}299 \cdot 8(68 \cdot 0) \\
(94 \cdot 9-923)\end{array}$ & $\begin{array}{l}159 \cdot 6(12 \cdot 4)^{* *} \\
(66 \cdot 6-206 \cdot 4)\end{array}$ \\
\hline Elastase $/ \alpha_{1} \mathrm{PI}(\mu \mathrm{g} / \mathrm{l})$ & $\begin{array}{l}89 \cdot 2(19 \cdot 3) \\
(39 \cdot 3-314)\end{array}$ & $\begin{array}{l}74 \cdot 8(6 \cdot 4) \\
(42 \cdot 1-118 \cdot 6)\end{array}$ & $\begin{array}{l}55 \cdot 8(4 \cdot 4) \\
(39 \cdot 5-75 \cdot 2)\end{array}$ \\
\hline \multicolumn{4}{|l|}{ Sputum: } \\
\hline Elastase activity (mU) & $\begin{array}{l}0.686(0.131) \\
(0.083-1.58)\end{array}$ & $\begin{array}{l}0.435(0.065)^{*} \\
(0.088-0.721)\end{array}$ & $\begin{array}{l}0.366(0.089) \\
(0.037-0.862)\end{array}$ \\
\hline Total elastase $(\mu \mathrm{g} / \mathrm{ml})$ & $\begin{array}{l}41 \cdot 7(7 \cdot 1) \\
(20-94)\end{array}$ & $\begin{array}{l}39 \cdot 0(5 \cdot 7) \\
(13 \cdot 2-84)\end{array}$ & $\begin{array}{l}31 \cdot 5(8 \cdot 2) \\
(10-93 \cdot 3)\end{array}$ \\
\hline IL-8(ng/ml) & $\begin{array}{l}121 \cdot 0(13 \cdot 2) \\
(29 \cdot 3-197)\end{array}$ & $\begin{array}{l}104 \cdot 9(13 \cdot 3) \\
(18-182)\end{array}$ & $\begin{array}{l}111 \cdot 2(17 \cdot 5) \\
(17 \cdot 2-207 \cdot 5)\end{array}$ \\
\hline
\end{tabular}

${ }^{*} \mathrm{p}<0.05 ;{ }^{* *} \mathrm{p}<0.005$ compared with baseline (Wilcoxon signed rank test).

One unit of active elastase is defined as the release of $1 \mathrm{M} p$-nitroanilide $/ \mathrm{min} / \mathrm{ml}$ from the substrate $N$-methoxysuccinyl-Ala-Ala-Pro-Val $p$-nitroanilide. significant. Values for plasma and sputum measurements and pulmonary function data are presented as mean (SE).

\section{Results}

CLINICAL RESPONSE TO RHDNASE

All 15 patients recruited to the study were evaluated at 11-12 weeks. Eleven completed the full 52 week study. One man aged 24 died during the study period and a further three (two women and one man aged 19-23 years) failed to return as scheduled for the 52 week visit. With the exception of the patient who died, information on the number of courses of intravenous antibiotics administered was available on all patients over the full duration of the study.

Little overall change in pulmonary function was observed either at 12 weeks or 52 weeks following initiation of rhDNase therapy (table 1 ), although considerable individual variation was observed. At 12 weeks seven (47\%) patients showed an increase in forced vital capacity (FVC) of $5 \%$ or more above baseline levels. Similar increases ( $>5 \%$ above baseline) in forced expiratory volume in one second $\left(\mathrm{FEV}_{1}\right)$ were observed in five of these patients. However, in four $(27 \%)$ patients a fall of $5 \%$ in both FVC and $\mathrm{FEV}_{1}$ was observed. By 52 weeks an improvement in $\mathrm{FEV}_{1}$ was maintained in only $27 \%$ of patients studied.

During the course of the study only two patients remained free of infective exacerbations. The remaining 12 patients required intravenous antibiotic therapy 1-8 times (mean number of infective episodes $=2 \cdot 7$ $(0 \cdot 6))$.

\section{ALTERATIONS IN ELASTASE LOAD FOLLOWING RHDNASE THERAPY}

There was a significant decrease in sputum elastase activity $(p<0.05)$ at 12 weeks following initiation of rhDNase therapy (table 2). However, there was no corresponding change in total (immunogenic) sputum or plasma elastase levels or in plasma levels of the elastase $/ \alpha_{1} P I$ complex at this time. The reduction in sputum elastase activity observed at 12 weeks was maintained at 52 weeks (table 2), at which time a significant reduction in total plasma elastase $(p<0.005)$ was also observed (figure). Although, as expected, there was a significant correlation between plasma levels of total elastase and elastase $/ \alpha_{1}$ PI complex $(r=0.65$, $\mathrm{p}<0.01$ ), the decrease in elastase $/ \alpha_{1}$ PI complex levels observed at 52 weeks did not reach statistical significance. No relationship between alterations in elastase levels and change in lung function was observed $(p=0.057)$.

\section{IL-8 LEVELS}

Nanogram quantities of IL-8 were readily detectable in baseline sputum samples from all patients. Nebulised rhDNase treatment for either 12 or 52 weeks did not alter sputum IL8 levels (table 2). IL- 8 was not detectable (assay detection limit $=18.0 \mathrm{pg} / \mathrm{ml}$ ) in corresponding plasma samples. 


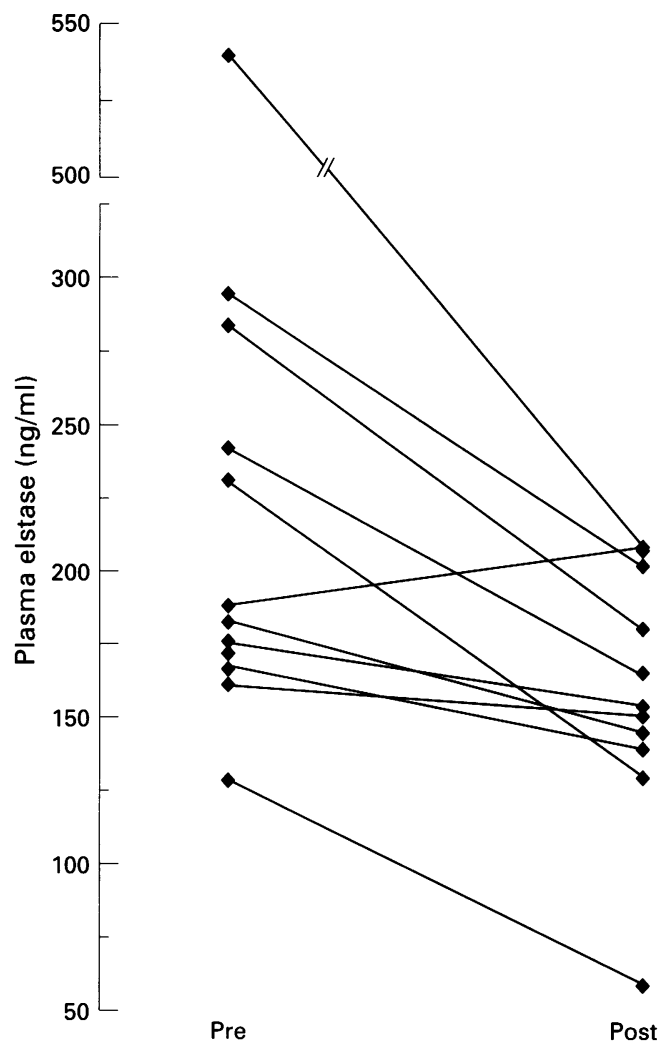

Plasma levels of neutrophil elastase before commencing treatment with DNase (pre) and at 52 weeks (post).

\section{Discussion}

Since its introduction in 1994, treatment with nebulised rhDNase has been shown to improve pulmonary function and patient well being and reduce the risk of infective exacerbations. ${ }^{6-9}$ Despite this apparent improvement in pulmonary status in cystic fibrosis patients, the effect of nebulised rhDNase on inflammation of the airways, which might support a longer term benefit, has not been extensively studied. Indeed, concerns have been raised that solubilisation of DNA in the airways may serve to release sequestered neutrophil elastase with potential adverse long term effects. Such concern arises from in vitro studies which demonstrate the release of active neutrophil elastase by rhDNase. ${ }^{2324}$ Results from the present study indicate that, in vivo, rhDNase significantly reduces rather than increases the neutrophil elastase load in patients with cystic fibrosis. Following 12 weeks of daily rhDNase administration, the levels of active elastase in the sputum were significantly reduced and by 52 weeks this reduction was reflected in decreased plasma levels of total neutrophil elastase. No change in total sputum elastase was noted, suggesting more effective inhibition within the lung of released elastase. Two preliminary reports have variously described both increases ${ }^{24}$ and decreases ${ }^{26}$ in sputum elastase activity following rhDNase therapy. Rochat and colleagues observed a significant increase in elastase activity following two weeks of rhDNase treatment in eight patients with cystic fibrosis. ${ }^{24}$ Shah et al reported a decrease in sputum elastase activity in a larger group of patients treated for 24 weeks. $^{26}$ However, patients who developed respiratory tract infections were excluded from the study. In the current study a decrease in elastase load was observed even though most of the patients experienced at least one infective exacerbation over the 52 week period. These data suggest that concerns over the possible deleterious effect of long term rhDNase treatment on elastase load in cystic fibrosis are largely unfounded.

Several studies have implicated IL-8 as a major mediator of neutrophil influx to the lung in inflammatory diseases. ${ }^{27} 28$ Khan and coworkers have recently reported the presence of high levels of IL-8 in the lungs of infants with cystic fibrosis in the absence of colonisation with common cystic fibrosis-related pathogens. ${ }^{12}$ These authors suggest that expression of IL- 8 by alveolar macrophages may be fundamental to the neutrophil dominated inflammatory response in the lungs of patients with cystic fibrosis. In the current study treatment with rhDNase was ineffective in reducing the high levels of IL-8 observed in sputum samples, suggesting that clearance of mucus from the airways may have little effect in reducing underlying neutrophil chemotaxis.

Although the main purpose of this study was to assess alterations in elastase load during rhDNase therapy, the lack of improvement in pulmonary function deserves comment. Both short term (1-2 weeks) and long term (up to two years) clinical trials report significant improvement over baseline values in both $\mathrm{FEV}_{1}$ and FVC in patients treated with rhDNase. While the extent of initial improvement observed within days of commencement of therapy $(10-15 \%)$ is not maintained, sustained increases of $4-7 \%$ over baseline are observed with daily administration of rhDNase over a two year period. ${ }^{29}$ In all studies, however, significant individual variation in response is observed. In the largest study carried out to date Fuchs et al indicate that $6-7 \%$ of treated patients actually experienced a decline in $\mathrm{FEV}_{1}$ of more than $10 \%{ }^{8}$ Davis has suggested that a significant improvement in $\mathrm{FEV}_{1}$ will be observed in less than $30 \%$ of patients, a figure similar to the $27 \%$ of patients in our study who displayed a sustained improvement in $\mathrm{FEV}_{1}$ over the 52 week study period. ${ }^{30}$ Other recent studies report results consistent with those observed here, suggesting that only a proportion of patients may derive sustained benefit in pulmonary function from DNase therapy. ${ }^{31}$

In summary, this study indicates that prolonged daily administration of rhDNase results in decreases in sputum elastase activity and in plasma levels of total neutrophil elastase, thus serving to reduce, rather than increase, the elastase load in patients with cystic fibrosis.

1 Chernick WS, Barbero GJ. Composition of tracheobronchial secretions in cystic fibrosis of the pancreas and bronchiectasis. Pediatrics 1959;24:739-45.

2 Chernick WS, Barbero GJ, Eichel HJ. In vitro evaluation of effect of enzymes on tracheobronchial secretions from patients with cystic fibrosis. Pediatrics 1961;27:589-96.

3 Lieberman J. Dornase aerosol effect on sputum viscosity in cases of cystic fibrosis. $\mathfrak{F} A M A 1968 ; 205: 312-3$.

4 Raskin P. Bronchospasm after inhalation of pancreatic dornase. Am Rev Respir Dis 1968;98:697-8.

5 Shak S, Capon DJ, Hellmiss R, Marsters SA, Baker CL Recombinant human DNase 1 reduces the viscosity of 
cystic fibrosis sputum. Proc Natl Acad Sci USA 1990;87: 9188-92.

6 Aitken ML, Berk W, MacDonald G, Shak S, Montgomery $\mathrm{AB}$, Smith A. Recombinant human DNase inhalation in normal subjects and patients with cystic fibrosis. $\mathcal{F} A M A$ 1992;267:1947-51

7 Ranasinha C, Assoufi B, Shak S, Christiansen D, Fuchs H, Empey D. Efficacy and safety of short-term administration of aerosolised recombinant human DNase 1 in adults with stable stage cystic fibrosis. Lancet 1993;342:199-202.

8 Fuchs HJ, Borowitz DS, Christiansen DH, Morris EM, Nash ML, Ramsey BW. Effect of aerosolised recombinant human DNase on exacerbations of respiratory symptoms and on pulmonary function in patients with cystic fibrosis. a Engl $₹$ Med 1994;331:637-42.

9 Shah PL, Scott SF, Fuchs HJ, Geddes DM, Hodson ME Medium term treatment of stable stage cystic fibrosis with Medium term treatment of stable stage cystic fibrosis with
recombinant human DNase 1. Thorax 1995;50:333-8.

10 Berger $M$. Inflammation in the lung in cystic fibrosis. A vicious cycle that does more harm than good? Clin Re Allergy 1991;9:119-42.

11 Cantin A. Cystic fibrosis lung inflammation: early, sustained and severe. Am f Respir Crit Care Med 1995;151:939-41.

12 Khan T Z, Wagener JS, Bost T, Martinez J, Accurso FJ, Riches DWH. Early pulmonary inflammation in infants with cystic fibrosis. Am $\mathcal{F}$ Respir Crit Care Med 1995;151: 1075-82.

13 Suter S, Schaad UB, Roux L, Nydegger UE, Waldvogel FA. Granulocyte neutral proteases and Pseudomonas elastase as possible causes of airway damage in patients with cystic possible causes of airway damage in
fibrosis. F Infect Dis 1984;149:523-31.

14 Janoff A, White R, Carp H, Harel S, Dearing R, Lee D. Lung injury induced by leucoyte proteases. $\mathrm{Am} \mathcal{F}$ Pathol 1979;97:111-29.

15 Amitani R, Wilson R, Rutman A, Read R, Ward C, Burnett $\mathrm{D}$, et al. Effects of human neutrophil elastase and Pseudomonas aeruginosa proteinases on human respiratory epithelium. Am 7 Respir Cell Mol Biol 1991;4:26-32.

16 Fick RB, Naegel GP, Squire SU, Wood RE, Gee BL Reynolds HY. Proteins of the cystic fibrosis respiratory tract. Fragmented immunoglobulin G opsonic antibody causing defective opsonophagocytosis. $\mathcal{F}$ Clin Invest 1984 74:236-48.

17 Berger M, Soerensen RJ, Tosi MF, Dearborn DG, Doring $\mathrm{G}$. Complement receptor expression on neutrophils at an inflammatory site, the Pseudomonas infected lung in cystic fibrosis. 7 Clin Invest 1989;84:1302-13.

18 Fick BB, Robbins RA, Squier SU, Schoderbek WE, Russ WD. Complement activation in cystic fibrosis respiratory fluids: in vivo and in vitro generation of $\mathrm{C} 5 \mathrm{a}$ and chemotactic activity. Pediatr Res 1986;20:1258-68.
19 Nakamura H, Yoshimura K, McElvaney NG, Crystal RG. Neutrophil elastase in respiratory epithelial lining fluid of individuals with cystic fibrosis induces interleukin- 8 gene expression in a human bronchial epithelial cell line. F Clin expression in a human brest $1992 ; 89: 1478-84$.

20 O'Connor CM, Gaffney K, Keane J, Southey A, Byrne $\mathrm{N}$, O'Mahoney S, et al. $\alpha_{1}$-proteinase inhibitor, elastase activity, and lung disease severity in cystic fibrosis. $\mathrm{Am}$ Rev Respir Dis 1993;148:1665-70.

21 Suter S, Schadd UB, Tegner K, Ohlsson K, Desgrandchamps D, Waldvogel FA. Levels of free granulocyte elastase in bronchial secretions from patients with cystic fibrosis: effect of antimicrobial treatment against $P_{\text {seudo- }}$ monas aeruginosa. F Infect Dis 1986;153:902-9.

22 Lieberman J, Trimmer BM, Kurnick NB. Substrate specificity of protease activities in purulent sputum. Lab Invest 1995;14:249-57.

23 Thomson AH. Human recombinant DNase in cystic fibrosis. F R Soc Med 1995;88:24-9.

24 Rochat T, Dayer F, Schlegel S, Barazzone C, Belli D, Filthuth I, et al. Effect of treatment with rhDNase on leukocytic elastase activity and quantitative sputum baceriology. Pediatr Pulmonol 1994; Suppl 10:237.

25 Pelletier A, Dimicoli J L, Boudier C, Bieth J G. Nonchromogenic hydrolysis of elastase and cathepsin $G$ pnitroanilide substrates by Pseudomonas aeruginosa elastase. Am $\mathcal{F}$ Respir Cell Mol Biol 1989;1:37-9.

26 Shah PL, Scott S, Knight RA, Hodson ME. Assessment of sputum sol phase elastase and interleukin-8 in cystic fibrosis patients treated with aerosolised recombinant human DNase 1. Am Rev Respir Dis 1994;149:A672.

27 Donnelly SC, Strieter RM, Kunkel SL, Walz A, Robertson CR, Carter DC, et al. Interleukin 8 and development of adult respiratory distress syndrome in at risk patient groups. Lancet 1993;341:643-7.

28 Carre PC, Mortenson RL, King TEJ, Noble PW, Sable C, Riches DWH. Increased expression of the interleukin-8 gene by alveolar macrophages in idiopathic pulmonary fibrosis. A potential mechanism for the recruitment and activation of neutrophils in lung fibrosis. $\mathcal{F}$ Clin Invest 1991;88:1802-10.

29 Shah PL, Scott SF, Geddes DM, Hodson ME. Two years experience with recombinant DNase 1 in the treatment of pulmonary disease in cystic fibrosis. Respir Med 1995; 89:499-502.

30 Davis PB. Evolution of therapy for cystic fibrosis. $N$ Engl f Med 1994;331:762-3.

31 Wojnarowski C, Eichler I, Frischer T, Storm K, Renner S, Koller DY, et al. Is it possible to predict lung function improvement due to aersolized recombinant human DNase therapy in patients with cystic fibrosis. Eur Respir f $1995 ; 8: 5745$ s. 